\title{
ANALISIS STRATEGI PEMASARAN DENGAN MENGGUNAKAN METODE SWOT PADA UNIVERSITAS MUHAMMADIYAH TANGERANG
}

\author{
Sena Atmaja, Resy Perwithasari \\ Universitas Muhammadiyah Tangerang \\ senaatmaja15@gmail.com
}

\begin{tabular}{l|l}
\hline Keyword & Abstract \\
\hline Marketing strategy, IFAS, EFAS & $\begin{array}{l}\text { The purpose of this study is to determine the right marketing strategy so } \\
\text { that the number of UMT new students is increasingly based on what } \\
\text { are the strengths, weaknesses, opportunities and threats that are } \\
\text { pursued by UMT. How to Understand UMT has great strength, the } \\
\text { strength is questioning because UMT is a Muhammadiyah charity } \\
\text { business. UMT also passed a huge opportunity which was high in the } \\
\text { public interest to continue their education up to college. The most } \\
\text { dominant weakness of UMT is the weak competence of lecturers, while } \\
\text { the major challenges related to UMT are the national economic } \\
\text { conditions that do not support economic improvement and the rapid } \\
\text { development of information technology. The position of the UMT } \\
\text { quadrant coordinate in the growth position means that UMT is a strong } \\
\text { and potential organization. The recommendations given are progressive, } \\
\text { meaning that the organization is in top condition and stable. Related to } \\
\text { really being expanded to continue the development of expansion, } \\
\text { growth and improvement, the most appropriate marketing strategy is to } \\
\text { support the development of strategies, including by improving the quality } \\
\text { of service, both for students, prospective students, by promoting values, } \\
\text { Islam and nobility. }\end{array}$ \\
\hline
\end{tabular}

C2019 JMB, All right reserved

\section{PENDAHULUAN}

Strategi pemasaran adalah suatu wujud rencana yang terurai dibidang pemasaran. Untuk memperoleh hasil yang optimal, strategi pemasaran ini mempunyai ruang lingkup yang luas di bidang pemasaran diantaranya adalah strategi dalam menghadapi persaingan, strategi harga, strategi produk, strategi pelayanan dan sebagainya. Perumusan strategi pemasaran didasarkan pada analisis yang menyeluruh terhadap pengaruh faktor-faktor lingkungan eksternal dan internal perusahaan.Lingkungan ekternal perusahaan setiap saat berubah dengan cepat sehingga melahirkan berbagai peluang dan ancaman baik yang datang dari pesaing utama maupun dari iklim bisnis yang senantiasa berubah.Konsekuensi perubahan faktor eksternal tersebut juga mengakibatkan perubahan faktor internal perusahaan, seperti perubahan terhadap kekuatan maupun kelemahan yang dimiliki perusahaan tersebut.

Perusahaan perlu mengenali kekuatan dan kelemahan perusahaan dalam persaingan hal ini akan sangat membantu dalam mengenali diri, serta memanfaatkan setiap peluang yang ada dan menghindari atau meminimalkan, dimana strategi pemasaran merupakan upaya mencari posisi pemasaran yang menguntungkan dalam suatu industri atau arena fundamental persaingan berlangsung. Pemasaran di suatu perusahaan, selain bertindak dinamis juga harus selalu menerapkan prinsip-prinsip yang unggul dan perusahaan harus meninggalkan kebiasaan-kebiasaan lama yang sudah 
tidak berlaku serta terus menerus melakukan inovasi. Karena sekarang bukanlah jaman dimana produsen membuat produksi tanpa mempertimbangkan kehendak konsumen, melainkan sebaliknya konsumen menentukan produk yang diinginkannya.

Dalam hal tersebut dapat digunakan analisis SWOT dengan tujuan mengindentifikasi berbagai faktor secara sistematis untuk merumuskan strategi perusahaan.Analisis ini didasarkan pada logika yang dapat memaksimalkan kekuatan (Strenghts) dan Peluang (Opportunities), namun secara bersamaan dapat meminimalkan kelemahan (Weaknesses) dan ancaman (Threats). Proses pengambilan keputusan strategis selalu berkaitan dengan pengembangan misi, tujuan, strategi, dan kebijakan perusahaan.

Universitas Muhammadiyah Tangerang (UMT) ialah suatu organisasi yang bergerak dalam bidang pendidikan. Universitas Muhammadiyah Tangerang adalah salah satu perguruan tinggi merupakan industri Jasa Pendidikan yang sedang berkembang. Setiap industri jasa pendidikan yang sedanga berkembang, memerlukan strategi pemasaran yang baik, agar UMT dapat bertahan dan unggul dari pesaing Perguruan Tinggi lainnya. Agar UMT dapat mencapai tujuannya perlu rencana strategi pemasaran dengan menggunakan metode analisis SWOT, dalam menganalisis maksudnya untuk mengetahui kekuatan, kelemahan, peluang serta ancaman yang dimiliki oleh UMT dan juga untuk mengetahui alternative strategi yang akan dijalankan. Tujuan analisis adalah untuk mengidentifikasi lingkungan intern dan ekstern UMT dalam iklim persaingan dengan Perguruan Tinggi yang bergerak dalam bidangyang sama.

\section{KERANGKA TEORI}

Peran strategi sangat penting dalam memasarkan produksebaik apapun segmentasi pasar sasaran, dan posisi pasar yang dilakukan tidak akan berjalan jika tidak diikuti dengan strategi yang tepat. Strategi adalah langkah-langkah yang harus dijalankan oleh suatu perusahaan untuk mencapai tujuan. Kadang langkah-langkah yang harus dihadapi terjal dan berliku-liku, namun adapula langkah yang relatif mudah (Kasmir, 2006:17I).

Strategi adalah pola fundamental dari tujuan sekarang dan yang terencana, penyebaran sumber daya, dan interaksi antara organisasi dengan pasar pesaing, dan faktor-faktor lingkungan lainnya (Simamora, 2000:214).

Strategi pemasaran merupakan suatu manajemen yang disusun untuk mempercepat pemecahan persoalan pemasaran dan membuat keputusan-keputusan yang bersifat strategis. Setiap fungsi manajemen memberikan kontribusi tertentu pada saat penyusunan strategi pada level yang berbeda. Pemasaran merupakan fungsi yang memiliki kontak paling besar dengan lingkungan eksternal, padahal perusahaan hanya memiliki kendali yang terbatas terhadap lingkungan eksternal. Oleh karena itu pemasaran memainkan peranan penting dalam pengembangan strategi.

Chandler (1962) dalam Freddy Rangkuti (2008 : 3) mengungkapkan bahwa strategi merupakan alat untuk mencapai tujuan perusahaan dalam kaitannya dengan tujuan jangka panjang, program tidak lanjut, serta prioritas alokasi sumber daya.

Steiner dan Miner (1977) dalam Freddy Rangkuti (2008 : 4) mengungkapkan bahwa strategi merupakan respon secara terus menerus maupun adaptif terhadap peluang dan ancaman eksternal serta kekuatan dan kelemahan internal yang dapat mempengaruhi organisasi.

Hamel dan Prahalad (1995) dalam Freddy Rangkuti (2008: 4 ) mengungkapkan bahwa strategi merupakan tindakan yang bersifat incremental (senantiasa meningkat) dan terus menurus dan dilakukan berdasarkan sudut pandang tentang apa yang diharapkan oleh para pelanggan di masa depan. Dengan demikian perencanaan strategi hampir selalu dimulai dari "apa yang dapat terjadi" bukan mulai dari "apa yang terjadi. Terjadi kecepatan inovasi pasar baru dan perubahan pola konsumen memerlukan kompetisi inti (core competencies). Perusahaan perlu mencari kompetisi inti didalam bisnis yang dilakukan. 
Menurut Philip Kotler pemasaran merupakan proses sosial di mana individu mendapatkan apa yang mereka butuhkan dan inginkan melalui penciptaan, penawaran, dan pertukaran yang bebas atas produk dan jasa yang bernilai dengan orang lain. Dalam bahasa yang ringkas, kita bisa mengatakan bahwa pemasaran adalah memuaskan kebutuhan dan keinginan orang dengan mendapatkan keuntungan.

Sedangkan manajemen pemasaran adalah proses pelaksanaan dan perencanaan suatu konsep dalam menentukan harga promosi distribusi harga jasa atau gagasan untuk menciptakan suatu peraturan untuk memenuhi tujuan pelanggan (Hendro, 20I I: 43I).

Menurut Carl McDaniel dan Roger Gate (200I: 4-5), pemasaran adalah proses merencanakan dan melaksanakan konsep, memberi harga, melakukan promosi dan menyalurkan ide, barang dan jasa untuk menciptakan pertukaran yang bisa memenuhi tujuan individu maupun organisasi dengan memerhatikan konsep pemasaran yang mensyaratkan orientasi konsumen, orientasi tujuan dan orientasi sistem

Dalam hubungan strategi pemasaran secara umum dapat dibedakan tiga jenis strategi pemasaran yang dapat ditempuh oleh perusahaan Assauri (2002:163-166) menyebutkan:

a. Strategi pemasaran yang tidak membedabedakan pasar (undifferentiated marketing). Dengan strategi ini perusahaan menganggap pasar sebagai suatu keseluruhan sehingga perusahaan hanya memperhatikan keutuhan konsumen secara umum. Salah satu keuntungan strategi ini adalah kemampuan perusahaan untuk menekan biaya sehingga dapat lebih ekonomis. Dan sebaliknya, kelemahannya adalah apabila banyak perusahaan lain juga menjalankan strategi ini, maka akan terjadi persaingan yang tajam untuk menguasai pasar tersebut (hyper competition), dan mengabaikan segment pasar kecil lainnya.

b. Strategi pemasaran yang membedabedakan pasar (differentiated marketing). Dengan strategi ini perusahaan hanya melayani keutuhan beberapa kelompok konsumen tertentu dengan jenis produk tertentu juga. Jadi, perusahaan atau produsen menghasilkan dan memasarkan produk yang berbeda-beda untuk tiap segment pasar. Keuntungan strategi pemasaran ini, penjualan dapat diharapkan akan lebih tinggi dengan posisi produk yang lebih baik disetiap segment pasar. Dan kelemahan nya adalah terdapat kecenderungan biaya akan lebih tinggi karena kenaikan biaya produksi untuk modifikasi produk, biaya administrasi, biaya promosi, dan biaya investasi.

c. Strategi pemasaran yang konseptual (concentrated marketing). Dengan strategi ini, perusahaan mengkhususkan pemasaran produknya dalam beberapa segment pasar dengan pertimbangan keteratasan sumber daya perusahaan. Keuntungan stategi ini, perusahaan dapat diharapkan akan memperoleh kedudukan atau posisi yang kuat didalam segment pasar tertentu yang dipilih. Dan kelemahannya adalah perusahaan akan menghadapi resiko yang besar bila hanya tergantung pada satu atau beberapa segment pasar saja

Berdasarkan kajian terhadap studi teoritis maka diuraikan kerangka penelitian dalam bagan berikut : 


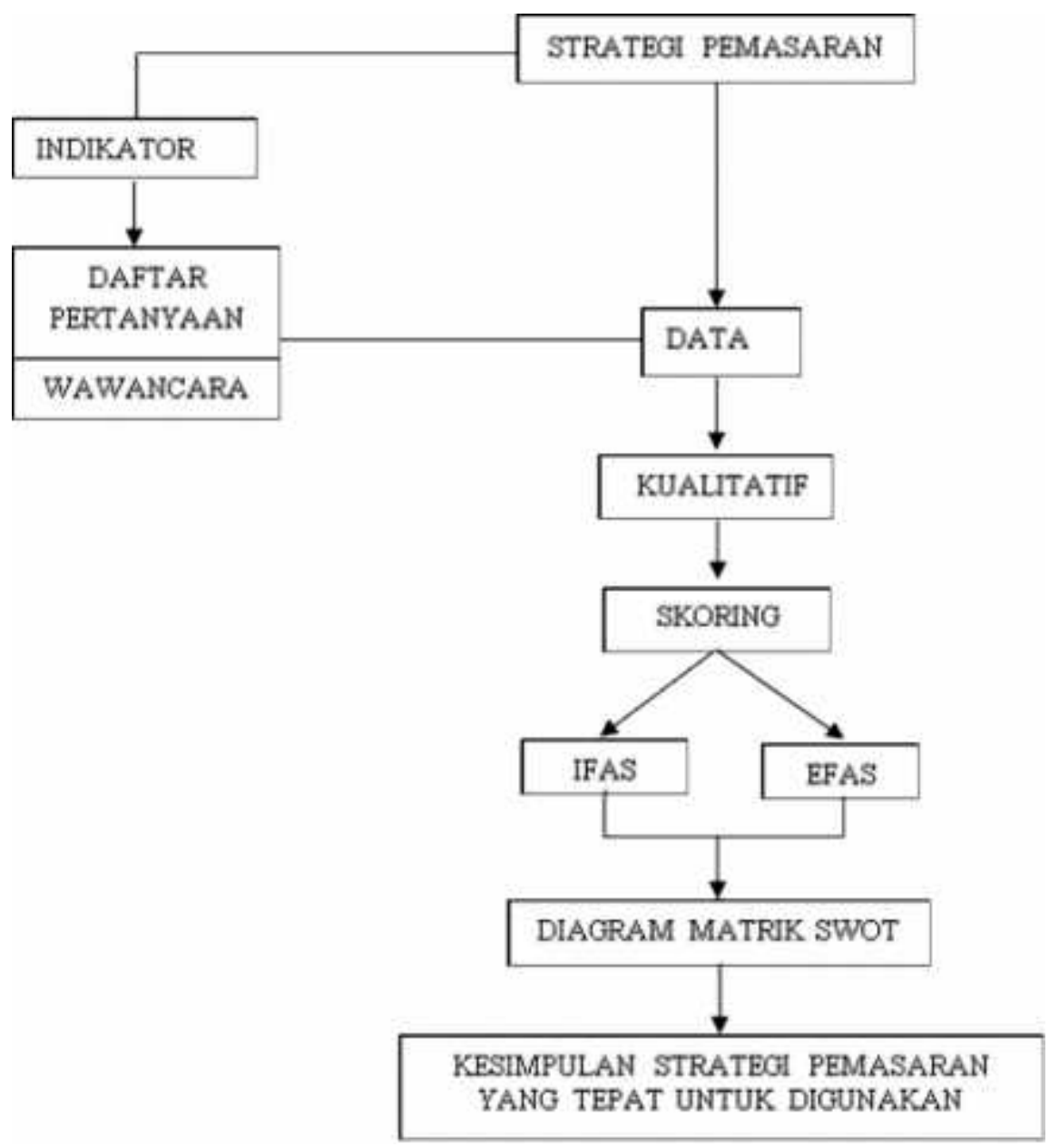

\section{Gambar 2. Bagan Kerangka Pikir}

Gambar 2 merupakan kerangka konseptual penelitian degan rumusan tujuan peelitan (I) untuk mengetahui apa yang menjadi kekuatan, kelemahan, peluang dan Ancaman yang dihadapi oleh UMT, (2) untuk mengetahui strategi apa yang paling tepat untuk semakin meningkatkan jumlah mahasiswa UMT.

\section{METODE PENELITIAN}

Objek penelitian ini adalah Universitas Muhammadiyah Tangerang (UMT) yang beralamat di Jl. Perintis Kemerdekaan 1/33 Cikokol Tangerang I5I I8 yang berdiri pada tanggal 03 Agustus 2009. Penelitian ini dilaksanakan pada bulan Juni, Juli, dan Agustus tahun 2016.

Metode dalam penelitian ini menggunakan metode kualitatif (Cresswell, 2016) dengan tujuan dari penggunaan metode kualitatif adalah untuk menemukan pola hubungan yang bersifat interaktif, menggambarkan realitas yang kompleks, serta untuk memperoleh pemahaman makna dan menemukan teori (Sugiyono, M. P. K., \& R\&D, 2014). Jenis data yang digunakan berupa data primer dan data sekunder dengan metode pengumpulan data menggunakan teknik wawancara, observasi, penyebaran kuisioner dan telaah pustaka (Nofrizal, 20I5).

Teknik pengambilan sampel menggunakan teknik menurut (Sugiyono, M. P. K., \& R\&D, 2014) merupakan metode pengambilan sampel dimana peneliti memiliki keriteria atau tujuan tertentu terhadap sampel yang akan dijadikan responden, pada penelitian ini menggunakan 13 responden yang terdiri dari 9 orang dekan, I pimpinan lembaga, dan 3 orang dari pimpinan rektorat. 
Metode analisis data menggunakan tahapan analisis eksternal (EFAS), analisis internal (IFAS) dan terakhir analisis posisi dengan matrik SWOT (Freddy Rangkuti, 20I4).

\section{HASIL DAN PEMBAHASAN}

\section{Indikator Faktor internal}

Faktor Internal yang berasal dari dalam lingkungan perusahaan yang berupa kekuatan dan kelemahan perusahaan.

\section{A. Kekuatan}

- UMT merupakan Perserikatan Muhammadiyah diakui handal, profesional dan menjamin pengelolaan lembaga pendidikannya berkembang maju di Nusantara.

- Lokasi UMT yang relatif strategis karena berada di pusat kota Tangerang akses transportasi mudah dan juga berada dalam wilayah yang memiliki kultur akademik yang baik sehingga mendukung proses pendidikan.

- Memiliki mahasiswa yang sebaran asalnya sangat variatif sehingga penyebaran informasi tentang UMT mudah.

- Adanya kelas shift sehingga Jam perkuliahan fleksibel.

- Memiliki dosen tetap yang cukup pada masingmasing program studi.

- Aktivitas mahasiswa yang cukup tinggi dalam berbagai kegiatan baik yang bersifat intrakulikuler maupun ekstrakulikuler.

\section{B. Kelemahan}

- Sumber pendanaan masih sangat bergantung pada mahasiswa.

- Kompetensi dosen tetap masih lemah.

- Sarana dan prasarana yang dimiliki masih perlu ditingkatkan.

- Jalinan kerjasama dengan pihak luar masih terbatas.

- Sistem Informasi Manajemen di UMT belum optimal.
- Status akreditasi masing-masing prodi belum maksimal.

\section{Indikator Faktor ekternal}

Faktor Eksternal yang berasal dari luar lingkungan perusahaan yang berupa Peluang dan ancaman yang dihadapi perusahaan.

\section{A. Peluang}

- Tingginya animo masyarakat untuk melanjutkan ke perguruan tinggi.

- Adanya tawaran DIKTI terkait dengan kegiatan mahasiswa dalam berbagai kompetisi di tingkat nasional.

- Adanya beasiswa dari pemerintah dan swasta untuk meningkatkan kualifikasi dosen.

- Banyaknya tawaran dari berbagai pihak untuk menjalin kerjasama.

- Tuntutan masyarakat dan pemerintah tentang status akreditasi masing-masing prodi

- Kepercayaan pemerintah dan masyarakat terhadap Universitas Muhammadiyah Tangerang cukup tinggi.

\section{B. Ancaman}

- Makin ketatnya tingkat persaingan antar perguruan tinggi.

- Tuntutan masyarakat terhadap perguruan tinggi untuk menghasilkan lulusan yang cepat memperoleh pekerjaan.

- Kondisi perekonomian nasional yang kurang mendukung akibat krisis.

- Stabilitas bidang politik, sosial, budaya, dan keamanan yang kurang kondusif.

- Cepatnya perkembangan teknologi informasi.

- Kompetisi untuk memperoleh pekerjaan bagi para lulusan makin ketat. 
Tabel I. IFAS

\begin{tabular}{|c|c|c|c|}
\hline Faktor-faktor Strategi Internal & Bobot & Rating & $\begin{array}{c}\text { Bobot X } \\
\text { Rating }\end{array}$ \\
\hline $\begin{array}{l}\text { Kekuatan : } \\
\text { - } \quad \text { UMT merupakan bagian Perserikatan } \\
\text { Muhammadiyah. } \\
\text { - } \quad \text { Lokasi UMT yang relatif strategis } \\
\text { - } \text { Memiliki mahasiswa yang sebaran asalnya } \\
\text { sangat variatif sehingga penyebaran } \\
\text { informasi tentang UMT mudah } \\
\text { - } \quad \text { Adanya kelas shift sehingga Jam perkuliahan } \\
\text { fleksibel. } \\
\text { - Memiliki dosen tetap yang cukup pada } \\
\text { masing-masing program studi. } \\
\text { - } \text { Aktivitas mahasiswa yang cukup tinggi } \\
\text { dalam berbagai kegiatan baik yang bersifat } \\
\text { intrakulikuler maupun ekstrakulikuler }\end{array}$ & $\begin{array}{l}0,20 \\
0,07 \\
0,05 \\
0,05 \\
0,15 \\
0,03\end{array}$ & $\begin{array}{l}2 \\
3 \\
2 \\
4\end{array}$ & $\begin{array}{l}0,15 \\
0,30 \\
0,12\end{array}$ \\
\hline Subtotal & 0,55 & & 1,75 \\
\hline $\begin{array}{l}\text { Kelemahan : } \\
\text { - Sumber pendanaan masih sangat } \\
\text { bergantung pada mahasiswa Saluran } \\
\text { distribusi } \\
\text { - } \text { Kompetensi dosen tetap masih lemah } \\
\text { - Sarana dan prasarana yang dimiliki masih } \\
\text { perlu ditingkatkan. } \\
\text { - Jalinan kerjasama dengan pihak luar masih } \\
\text { terbatas. } \\
\text { - Sistem Informasi Manajemen di UMT } \\
\text { belum optimal } \\
\text { - Status akreditasi masing-masing prodi } \\
\text { belum maksimal }\end{array}$ & $\begin{array}{l}0,10 \\
0,15 \\
0,02 \\
0,08 \\
0,05\end{array}$ & $\begin{array}{l}2 \\
1 \\
3 \\
2\end{array}$ & $\begin{array}{l}0,20 \\
0,15 \\
0,06 \\
0,16 \\
0,15\end{array}$ \\
\hline Subtotal & 0,45 & & 0,77 \\
\hline TOTAL & 1,00 & & 2,52 \\
\hline
\end{tabular}

Dari hasil analisis pada tabel I diketahui faktor kekuatan mempunyai total nilai skor I,75 dan Faktor kelemahan mempunyai total nilai skor 0,77. Total skor IFAS sebesar 2,52 menunjukkan bahwa UMT memiliki kekuatan besar untuk menghadapi peluang dan ancaman.

Indikator dari faktor kekuatan yang paling dominan adalah "UMT merupakan bagian Persyarikatan Muhammadiyah" dengan skor 0,80 . Artinya nama dan brand image dari persyarikatan Muhammadiyah memberikan citra yang sangat positif terhadap kekuatan internal UMT, efek positif persyarikatan Muhammadiyah timbul karena persyarikatan Muhammadiyah merupakan salahsatu organisasi islam terbesar di Indonesia yang dalam pelaksanaan dakwahnya dikenal sangat memperhatikan pendidikan mulai dari pendidikan usia dini hinga pendidikan tinggi, terbukti sampai dengan tahun 2016 Muhammadiyah sudah memiliki 19.95I Sekolah terdiri dari TK sampai SMA/SMK/MA, 102 Pesantren, dan 176 Perguruan Tinggi (Laporan PP Muhammadiyah di Muktamar 47)

Indikator dari faktor kelemahan yang paling dominan adalah "kompetensi dosen yang masih lemah" dengan skor 0,20, Artinya UMT masih harus berbenah meningkatkan kualitas dosen dari sisi kompetensi. Dosen sebagai ujung tombak pelayanan dalam dunia pendidikan tinggi merupakan sesuatu yang sangat penting peranannya, peranan ini bisa menjadi titik kelemahan dan juga bisa menjadi kekuatan tergantung pada kompetensi yang dimiliki oleh dosen. Maka dari itu agar kelemahan ini berbalik menjdi kekuatan UMT 
harus mengeluarkan kebijakan yang bertujuan untuk meningkatkan kompetensi dosen yang dimiliki.

Tabel 2. EFAS

\begin{tabular}{|c|c|c|c|}
\hline Faktor-faktor Strategi Eksternal & Bobot & Rating & $\begin{array}{c}\text { Bobot } X \\
\text { Rating }\end{array}$ \\
\hline $\begin{array}{l}\text { Peluang: } \\
\text { - Tingginya animo masyarakat untuk } \\
\text { melanjutkan pendidikan sampai ke } \\
\text { perguruan tinggi. } \\
\text { - Adanya tawaran DIKTI terkait dengan } \\
\text { kegiatan mahasiswa dalam berbagai } \\
\text { kompetisi di tingkat nasional. } \\
\text { - } \text { Adanya beasiswa dari pemerintah dan } \\
\text { swasta untuk meningkatkan kualifikasi } \\
\text { dosen. } \\
\text { - Banyaknya tawaran dari berbagai } \\
\text { pihak untuk menjalin kerjasama. } \\
\text { - Tuntutan masyarakat dan pemerintah } \\
\text { tentang status akreditasi masing- } \\
\text { masing prodi. } \\
\text { Kepercayaan pemerintah dan } \\
\text { masyarakat terhadap Universitas } \\
\text { Muhammadiyah Tangerang cukup } \\
\text { tinggi masing-masing program studi. }\end{array}$ & $\begin{array}{l}0,10 \\
0,08 \\
0,05\end{array}$ & 2 & $\begin{array}{l}0,16 \\
0,15\end{array}$ \\
\hline Subtotal & 0,53 & & $\mid, 61$ \\
\hline $\begin{array}{l}\text { Ancaman : } \\
\text { - Makin ketatnya tingkat persaingan } \\
\text { antar perguruan tinggi. } \\
\text { - Tuntutan masyarakat terhadap } \\
\text { perguruan tinggi untuk menghasilkan } \\
\text { lulusan yang cepat memperoleh } \\
\text { pekerjaan. } \\
\text { - Kondisi perekonomian nasional yang } \\
\text { kurang mendukung akibat krisis. } \\
\text { - Stabilitas bidang politik, sosial, budaya, } \\
\text { - dan keamanan yang kurang kondusif. } \\
\text { informasi. } \\
\text { - Kompetisi untuk memperoleh } \\
\text { pekerjaan bagi para lulusan makin } \\
\text { ketat. }\end{array}$ & $\begin{array}{l}0,03 \\
0,10 \\
0,09\end{array}$ & $\begin{array}{l}1 \\
1\end{array}$ & $\begin{array}{l}0,05 \\
0,15\end{array}$ \\
\hline Subtotal & 0,47 & & 0,90 \\
\hline TOTAL & 1,00 & & 2,51 \\
\hline
\end{tabular}

Dari hasil analisis pada tabel 2 diketahui faktor peluang mempunyai total nilai skor I,6I dan Faktor ancaman mempunyai total nilai skor 0,90. Total skor EFAS sebesar 2,5I menunjukkan bahwa UMT memiliki peluang yang besar.

Indikator dari faktor peluang yang paling dominan adalah "tingginya animo masyarakat untuk melanjutkan ke perguruan tinggi” dengan 
skor 0,80. Artinya ada pertumbuhan kesadaran pada masyarakat dalam hal melanjutkan pendidikan sampai pada tingkat perguruan tinggi, hal ini merupakan kesempatan yang harus bisa dimanfaatkan oleh UMT dengan cara melakukan komunikasi promosi yang efektif agar masyarakat yang sadar terhadap kebutuhan pendidikan tinggi tersebut menjatuhkan pilihan untuk melanjutkan pendidikannya di UMT.

Indikator dari faktor ancaman yang paling dominan adalah "Kondisi perekonomian nasional yang kurang mendukung akibat krisis" dan "Cepatnya perkembangan teknologi informasi” dengan sama - sama memiliki skor 0,20. Dalam hal lemahnya perekonomian nasional, dampak yang akan dirasakan oleh UMT adalah melambatnya pembayaran dari mahasiswa sehingga akan mengganggu operasional organisasi, mensiasati ini UMT haruslah mengeluarkan kebijaakan rekayasa pembayaran yang meringankan mahasiswa agar keterlambatan pembayaran bisa diminimalisir sehingga tidak mengganggu operasional oeganisasi. Dalam hal "Cepatnya perkembangan teknologi informasi” UMT harus mampu mengubah ini menjadi sebuah tantangan, penyesuaian cara kerja organisasi UMT harus berorientasi pada digitalisasi agar tak menjadi korban era distrupsi.

Posisi kordinat kuadran UMT dapat diketahui dengan cara menghitung selisih dari total faktor kekuatan dengan total faktor kelemahan juga selisih dari total skor peluang dengan total skor ancaman

IFAS $=$ Total Skor Kekuatan - Total Skor Kelemahan

$$
\begin{aligned}
& =1,75-0,77 \\
& =0,98
\end{aligned}
$$

EFAS $=$ Total Skor Peluang - Total Skor

Ancaman

$$
\begin{aligned}
& =I, 6 I-0,90 \\
& =0,7 I
\end{aligned}
$$

dari hasil identifikasi faktor-faktor tersebut maka posisi kordinat kuadran UMT dapat digambarkan dalam diagram SWOT sebagai berikut :

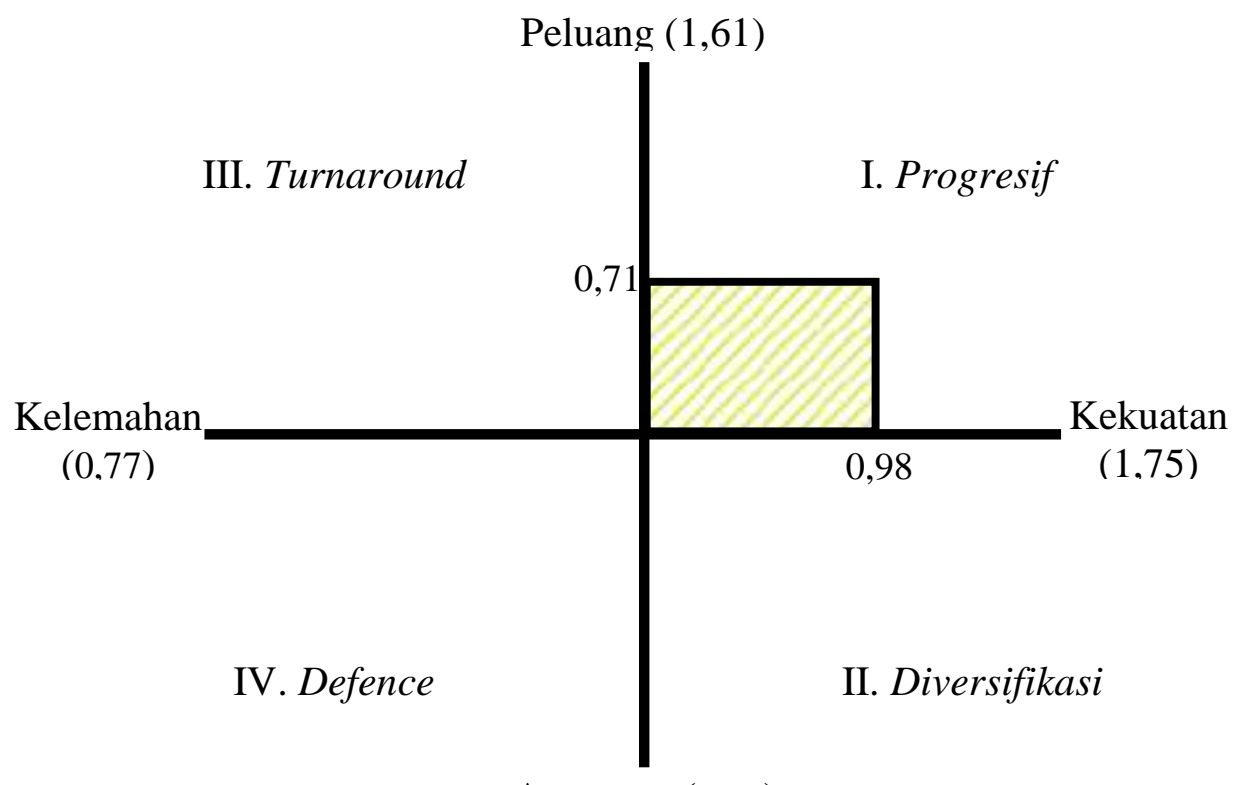

Ancaman $(0,90)$ 
Bisa dilihat bahwa posisi UMT berada pada kuadran I (positif-positif) atau sedang dalam keadaan growth, ini membuktikan bahwa UMT merupakan sebuah organisasi yang kuat dan berpeluang. Rekomendasi taktik yang diberikan ialah progresif, artinya organisasi

\section{PENUTUP}

A. Kesimpulan

Dari hasil pembahasan diatas maka disimpulkan :

I. Kekuatan terbesar yang dimiliki UMT adalah UMT merupakan bagian Perserikatan Muhammadiyah.

2. Peluang terbesar yang harus segera direspon UMT adalah tingginya animo masyarakat untuk melanjutkan pendidikan sampai ke perguruan tinggi.

3. Kelemahan terbesar yang dimiliki UMT adalah kompetensi dosen tetap masih lemah.

4. Ancaman terbesar yang akan dihadapi UMT adalah kondisi perekonomian nasional yang kurang mendukung akibat krisis dan arus perkembangan teknologi informasi yang semakin cepat.

5. Posisi kuadran matrik SWOT UMT berada pada posisi growth, maka dapat menciptakan kebijakan strategi utama yaitu strategi SO (Strenght dan Opportunities). Kebijakan strategi ini menggunakan kekuatan yang dimiliki UMT untuk meraih peluang yang ada.

\section{B. Rekomendasi}

Strategi umum yang dapat dilakukan oleh perusahaan adalah menggunakan kekuatan perusahaan untuk mengambil setiap keunggulan pada peluang yang ada, berikut strategi yang bisa dalakukan oleh UMT :

I. Meningkatkan kualitas pelayanan, baik terhadap mahasiswa ataupun calon mahasiswa dengan mengedepankan nilai-nilai islami dan kemuhammadiyahan.

2. Menambah sarana prasarana untuk menunjang kegiatan belajar mengajar di Universitas Muhammadiyah Tangerang. dalam kondisi prima dan mantap. Sehingga benar-benar dimungkinkan untuk terus menjalankan ekspansi, memperbesar pertumbuhan dan meraih kemajuan secara maksimal.

3. Memperbaiki kurikulum pembelajaran dengan cara meningkatkan kompetensi Dosen tetap.

4. Menambah Program studi baru dan meningkatkan status akreditasi pada masingmasing program studi yang sudah ada.

5. Memasuki segmen pasar baru, sampai dengan saat ini mahasiswa UMT masih didominasi oleh mahasiswa yang sudah memiliki pekerjaan maka dari itu UMT harus mulai melakukan promosi dengan fokus pada segmen pasar freshgraduate.

6. Mendukung kegiatan intrakulikuler dan ekstrakulikuler pada mahasiswa yang aktif dan berprestasi dengan cara memberikan beasiswa kepada mahasiswa.

\section{DAFTAR PUSTAKA}

Andriani, Dewi. 2004. Pengembangan Strategi Pemasaran Pada Tahap Daur Hidup Produk. Jurnal Ilmiah "Manajemen \& Bisnis".

Afrillita, Nur. 2013. Analisis SWOT Dalam Menentukan Strategi Pemasaran Sepeda Motor Pada PT. Samekarindo Indah Di Samarinda. ejournal Administrasi Bisnis, Volume I, Nomor I.

Amrullah \& Haris Budiyono. 2004. Pengantar Manajemen. Graha Ilmu. Yogyakarta

Bangs, David H. 1995. Pedoman Menyusun Rencana Pemasaran. Edisi III. Erlangga. Jakarta.

Carl McDaniel, Roger Gate, 200I. Riset Pemasaran Kontemporer, Jakarta: Salemba Empat

Hendro, 20II. A Smart And Good Entrepeneur, Media Pressindo, Yogyakarta

Hidayat, Aprihatiningrum. 20I2. Strategi Pemasaran Produk Pepaya Sunfresh Jenis 
California Grading B dan C di Pasar Tradisional Kawasan Jabotabek. Journal of Management and Bisiness Review, Vol 9, No I. J

Hunger, David \& Whellen, L. Thomas. 2003. Manajemen Strategis. Andi. Yogyakarta

Kotler, Philip. Alih Bahasa : Hendra Teguh, SE.,Ak da Ronny Rusli, SE.,Ak. 1997. Manajemen Pemasaran. Edisi Bahasa Indonesia. Jilid I. PT. Prenhallindo. Jakarta. . 1998. Dasar-dasar Pemasaran. Edisi Bahasa Indonesia. Jilid 2. PT. Prenhallindo. Jakarta

2000. Manajemen Pemasaran. Edisi. Milenium. Indeks Jakarta.

Rangkuti, Freddy. 20I4. Analisis SWOT Teknik Membedah Kasus Bisnis. Gramedia. Jakarta.

2008. Analisis SWOT Teknik Membedah Kasus Bisnis. Gramedia. Jakarta.

Stanton, William. J. 2003. Prinsip Pemasaran. Erlangga. Jakarta

Stoner, James A.F \& Edward Freeman. 2004. Manajemen. Intermedia. Yogyakarta

Sofjan Assauri, 2002. Manajemen Pemasaran Dasar, Konsep, dan Strategi, Raja Grafindo Persada, Jakarta. 